\title{
Secreted phosphoprotein-1 accelerates the progression of human colorectal cancer through activating $\beta$-catenin signaling
}

\author{
JIANZHONG YI* , YUNGENG LIU*, LEI ZHANG and CHUANFA FANG \\ Department of Gastroenteric Hernia, Ganzhou People's Hospital, Ganzhou, Jiangxi 341000, P.R. China
}

Received April 19, 2020; Accepted December 7, 2020

DOI: 10.3892/ol.2021.12633

\begin{abstract}
Colorectal cancer (CRC) is a common malignant tumor of the digestive tract and one of the leading causes of cancer-associated mortality. Secreted phosphoprotein-1 (SPP-1) is overexpressed in CRC and promotes cancer progression, but the underlying mechanisms underlying SPP-1 function remain unclear. The present study aimed to explore the effects of Wnt/ $\beta$-catenin signaling in SPP-1-induced CRC progression. The expression patterns of SPP-1 in CRC tissues were examined using reverse transcription-quantitative (RT-q)PCR, western blotting and immunohistochemistry. SPP-1 expression in cells was assessed using RT-qPCR and western blotting. Cell-Counting Kit-8, flow cytometry and tumor-burdened mice experiments were used to determine cell proliferation, apoptosis and in vivo tumor formation abilities. The results showed that SPP-1 expression was markedly elevated in CRC tissues and cells compared with that in normal colorectal tissues and cells. High expression of SPP-1 was associated with advanced clinical process and low overall survival rate in patients with CRC. Besides, SPP-1 could interact with $\beta$-catenin and positively regulated $\beta$-catenin protein expression, and enhanced its nuclear accumulation. Moreover, SPP-1-upregulation significantly enhanced cell proliferation and in vivo tumor formation ability, and reduced apoptosis, whereas these effects were all abolished when $\beta$-catenin was silenced. Overall, the present study revealed that SPP-1 promoted the progression of CRC in a $\beta$-catenin-dependent manner.
\end{abstract}

\section{Introduction}

Human colorectal cancer (CRC) is the third most common malignant tumor and the fourth most common cause of

Correspondence to: Dr Chuanfa Fang, Department of Gastroenteric Hernia, Ganzhou People's Hospital, 16 Meiguan Avenue, Zhanggong, Ganzhou, Jiangxi 341000, P.R. China

E-mail: liaoyongbin711@163.com

*Contributed equally

Key words: secreted phosphoprotein-1, $\beta$-catenin, colorectal cancer, proliferation, tumor formation cancer-associated mortality in the world $(1,2)$. Notably, the incidence rate of CRC in younger people has increased in past years in China (3). Although notable progress has been made in the therapy and diagnosis of CRC, the therapeutic response and prognosis are still unsatisfactory with a 5-year survival rate of $\sim 50 \%$ (4). Therefore, exploration of the mechanism underlying CRC progression and identifying effective molecular targets are of important to improve the treatment of CRC.

It is well documented that the $\mathrm{Wnt} / \beta$-catenin signaling pathway is frequently hyper-activated in cancer and is strongly implicated in carcinogenesis, including CRC $(5,6)$. Inhibition of the Wnt/ $\beta$-catenin signaling pathway is a potential antitumor target for CRC (7). In the absence of Wnt, $\beta$-catenin protein is retained in cytoplasm through forming a protein complex with axis inhibitor (Axin), adenomatous polyposis coil (APC), casein kinase $1 \alpha$ and glycogen synthase kinase $3 \beta$ (8). However, the free $\beta$-catenin level is elevated in cytoplasm and then translocates into the nucleus when Wnt signaling is activated, followed by the increased transcription of its target genes, such as c-myc and cyclin D1, through interacting with the T-cell factor/lymphoid enhancer factor family of transcription factors $(9,10)$. Although the inactivating mutation of APC is considered an important factor for $\mathrm{Wnt} / \beta$-catenin activation in CRC (11-13), other factors or genes that induce Wnt/ $\beta$-catenin signaling activation in CRC still need to be clarified.

Secreted phosphoprotein-1 (SPP-1), also known as osteopontin, is located at $4 \mathrm{q} 22.1$ and a multifunctional member of the small integrin-binding ligand N-linked glycoprotein family (14). Evidence has demonstrated that SPP-1 is upregulated in various malignant tumors $(15,16)$, including CRC (17). For example, $\mathrm{Xu}$ et al (17) used bioinformatics methods and found that SPP-1 was significantly overexpressed in CRC tissues, and its high expression is closely associated with the advanced clinical process and poor prognosis in patients with CRC. Further experiments showed that downregulation of SPP-1 significantly repressed CRC cell viability, migration and tumor growth and induced apoptosis. Moreover, Huang et al (18) demonstrated that SPP-1-upregulation resulted in significant enhancements in cell proliferation, migration and invasion, and inhibited apoptosis and autophagy through regulating MAPK signaling. These findings demonstrate that SPP-1 plays an oncogenic role in CRC progression, but the underlying mechanisms remain unclear.

The present study aimed to explore the role of the Wnt/ $\beta$-catenin signaling pathway in SPP-1-induced CRC 
progression with in vivo and in vitro experiments. Our results demonstrated that $\beta$-catenin was an indispensable factor for SPP-1-mediated CRC progression.

\section{Materials and methods}

Colorectal tissue specimens. Primary CRC tissues and adjacent normal colorectal tissues ( $>2 \mathrm{~cm}$ from the tumor tissues) were obtained from 200 patients with CRC who underwent colectomy from May 2009 to May 2017. All patients signed the informed consent and received colectomy as the first treatment method. Patients were excluded if they suffered from other malignant tumors or if they received radiotherapy and/or chemotherapy before surgery. Tumor-Node-Metastasis (TNM) stage was evaluated according to previously reported (19). The fresh tissues were then immediately immersed in liquid nitrogen $\left(-196^{\circ} \mathrm{C}\right)$ until analysis. Experiments involving human samples were performed according to the Helsinki Declaration and approved by The Ethical Committee of Ganzhou People's Hospital (approval no. Ky2019015).

Immunohistochemistry (IHC). For IHC, the routine three-step procedure was performed as previously described (20) with the primary antibody against SPP-1 (cat. no. ab8448; Abcam). The staining of SPP-1 was determined by three pathologists independent from the present study in a blinded manner. The extent of positively stained cells was scored as: 0 For $0-5 \%$, 1 for $6-25 \%, 2$ for $26-50 \%, 3$ for $51-75 \%$, and 4 for $76-100 \%$. The staining intensity was scored as: 0 for negative staining, 1 for weak staining, 2 for moderate staining, and 3 for strong staining. The extent score was multiplied with intensity score to obtain the total score of SPP-1 staining in colon tissues. Total score of SPP-1 staining $\leq$ medium score (9 points) of the total samples was defined as low expression, and $>$ medium score was defined as high expression.

Cell culture conditions. Human normal colon cell line CCD-18Co was purchased from The Cell Bank of the Chinese Academy of Sciences and cultured in RPMI-1640 medium with 10\% fetal serum bovine (FBS) (both Thermo Fisher Scientific, Inc.). Three human CRC cell lines, including SW620, COLO 205 and SW480 were obtained from BeNa Culture Collection. SW620 and COLO 205 cells were cultured in RPMI-1640 medium and SW480 cells were grown in DMEM-H medium (Thermo Fisher Scientific, Inc.) with 10\% FBS. All cells were maintained at $37^{\circ} \mathrm{C}$ with $5 \% \mathrm{CO}_{2}$.

Alteration of gene expression in cells. To upregulate SPP-1 expression, SW480 cells were infected with the overexpression lentiviral vector (OE-SPP-1; Shanghai GenePharma Co., Ltd.) at a multiplicity of infection of 5 and incubated with $\mathrm{G} 418(100 \mu \mathrm{g} / \mathrm{ml})$ for 14 days at $37^{\circ} \mathrm{C}$ to select the stably overexpressed cells. To silence $\beta$-catenin expression, three lentiviral vectors (sh- $\beta$-catenin-1/-2/-3; OriGene Technologies, Inc.) and pumomycin ( $7 \mu \mathrm{g} / \mathrm{ml}$, incubation for 14 days) were used to select the stably transfected cells. The 2 nd generationally stable cell lines were used for further studies. Two small interfering (si)RNAs of SPP-1 (si-SPP-1-1/-2; 100 pmol/6-well plates) and the scrambled control (si-NC) purchased from OriGene Technologies, Inc. were used to downregulate SPP-1 expression using Lipofectamine ${ }^{\circledR} 2000$ (Thermo Fisher Scientific, Inc.) at $37^{\circ} \mathrm{C}$. After $48 \mathrm{~h}$ of transfection, the cells were harvested for further analysis. The si sequences were as follows: si-SPP-1-1, 5'-UCAUAUUCUGAAUCUCAUCCU-3'; si-SPP-1-2: 5'-AGUUUCAACCGUCUUAAUCAG-3'.

RNA extraction and reverse transcription-quantitative (RT- $q$ ) $P C R$. Total RNA was extracted from snap-frozen tissues or cultured cells using TRIzol ${ }^{\circledR}$ reagent (Invitrogen; Thermo Fisher Scientific, Inc.). The first-strand cDNA was synthesized with random primers (Beijing Solarbio Science \& Technology Co., Ltd.) using TaqMan Reverse Transcription kit (Takara Biotechnology Co., Ltd.) at $42^{\circ} \mathrm{C}$ for $60 \mathrm{~min}$. After that, the RT-qPCR was carried out with SYBR Green of The SuperScript ${ }^{\circledR}$ III One-Step RT-PCR system (Thermo Fisher Scientific, Inc.). Primers for SPP-1 were 5'-GAATCTCCTAGC CCCACAGACC-3' (sense) and 5'-ACTCCTCGCTTTCCA TGTGTG-3' (antisense); primers for $\beta$-catenin were 5 '-GCG CCATTTTAAGCCTCTCG-3' and 5'-GGCCATGTCCAA CTCCATCA-3'; primers for GAPDH were 5'-CCACTAGGC GCTCACTGTTCTC-3' (sense) and ACTCCGACCTTCACC TTCCC-3' (antisense). Reaction conditions were as follows: $94^{\circ} \mathrm{C}$ For $5 \mathrm{~min}$, followed by amplification for 40 cycles $\left(94^{\circ} \mathrm{C}\right.$ for $30 \mathrm{sec}, 57^{\circ} \mathrm{C}$ for $30 \mathrm{sec}$ and $72^{\circ} \mathrm{C}$ for $30 \mathrm{sec}$ ), and a final step at $72^{\circ} \mathrm{C}$ for $5 \mathrm{~min}$. The levels of mRNAs were calculated using the $2^{-\triangle \Delta C q}$ method (21). GAPDH was used as endogenous control to normalize the mRNA levels of SPP- 1 and $\beta$-catenin.

Western blotting. Protein was extracted using RIPA lysis buffer (Shanghai Yeasen Biotechnology Co., Ltd.) and protease and phosphatase inhibitors (Beijing Solarbio Science \& Technology Co., Ltd.). After centrifugation at $4^{\circ} \mathrm{C}$ for $25 \mathrm{~min}$ at $12,000 \mathrm{xg}$, the protein samples were quantified by using the Bicinchoninic acid Protein Assay kit (Thermo Fisher Scientific, Inc.) and then $25 \mu \mathrm{g}$ protein from each group was loaded per lane and separated by $10 \%$ SDS-PAGE. After that, the proteins were transferred into the polyvinylidene difluoride membranes (Thermo Fisher Scientific), following by being blocked with 5\% non-fat milk for $1 \mathrm{~h}$ at room temperature. Then, the membranes were probed with the indicated primary antibodies, SPP-1 (1:3,000 dilution; cat. no. ab844; Abcam), Axin (1:3,000 dilution; cat. no. ab32197; Abcam), $\beta$-catenin (1:2,000 dilution; cat. no. ab16051; Abcam), Frz (1:1,000 dilution; cat. no. AF1617; R\&D Systems, Inc.), DVL1 (1:2,000 dilution; cat. no. TA329899; OriGene Technologies, Inc.), TCF (1:2,500 dilution; cat. no. \#9383; Cell Signaling Technology, Inc.), c-myc (1:2,000 dilution; cat. no. M4439; Sigma-Aldrich; Merck KGaA), APC (1:2,000 dilution; cat. no. ab15270; Abcam) and GAPDH (1:6,000 dilution; cat. no. 2118; Cell Signaling Technology, Inc.) at $4^{\circ} \mathrm{C}$ overnight and the HRP-conjugated secondary antibodies (1:10,000 dilution; cat. no. SA00001-1 and SA00001-2; ProteinTech Group, Inc.) for $1 \mathrm{~h}$ at room temperature in succession. The protein signaling was visualized using electrochemiluminescence reagent (EMD Millipore) and quantified by ImageJ software (version 1.48; National Institutes of Health).

Co-immunoprecipitation (Co-IP). The interaction between different proteins was assessed using a Co-IP assay. SW480 cells were rinsed with cold PBS and lysed in IP lysis buffer 
(Beijing Solarbio Science \& Technology Co., Ltd.), followed by centrifugation at $4^{\circ} \mathrm{C}$ for $25 \mathrm{~min}$ at $12,000 \mathrm{x}$. Then, the proteins $(200 \mu \mathrm{g})$ were incubated with $10 \mu \mathrm{l}$ of Dynabeads ${ }^{\circledR}$ protein $\mathrm{G}$ (Thermo Fisher Scientific, Inc.) for $1 \mathrm{~h}$. Next, the proteins were incubated with $2 \mu \mathrm{g}$ of SPP-1 antibody or IgG antibody (negative control) overnight at $4^{\circ} \mathrm{C}$, and Dynabeads ${ }^{\circledR}$ protein $\mathrm{G}$ for $1 \mathrm{~h}$. The immunocomplex was washed five times with IP lysis buffer and boiled at $100^{\circ} \mathrm{C}$ for $8 \mathrm{~min}$, and then subjected to western blotting analysis.

Immunofluorescence microscopy. SW480 cells with and without stable SPP-1 stable overexpression were cultured in culture glass slides in 24 -well plates and incubated at $37^{\circ} \mathrm{C}$ for $48 \mathrm{~h}$. Then, the cells were fixed with $4 \%$ paraformaldehyde for $15 \mathrm{~min}$ at room temperature, followed by incubation with $1 \%$ Triton-100 for $10 \mathrm{~min}$ for cell membrane permeabilizing. Next, the cells were rinsed with phosphate buffer, blocked with 5\% goat serum (Beijing Solarbio Science \& Technology Co., Ltd.) for $1 \mathrm{~h}$ at room temperature and incubated with the primary antibody against $\beta$-catenin (cat. no. ab16051; Abcam) overnight at $4^{\circ} \mathrm{C}$ and the Alexa Fluor ${ }^{\circledR} 488$ Conjugated secondary antibody (1:1,000 dilution; cat. no. 4412; Cell Signaling Technology, Inc.) for $1 \mathrm{~h}$ at room temperature. DAPI (Invitrogen; Thermo Fisher Scientific, Inc.) was used for nuclear staining at a concentration of 1:5,000 for $5 \mathrm{~min}$ at room temperature. The subcellular location of $\beta$-catenin was analyzed on a laser scanning microscope (magnification, x60; TCSSP2-AOBS-MP; Leica Microsystems, Inc.).

Cell proliferation detection. After $6 \mathrm{~h}$ of cell transfection with OE-SPP-1, OE-NC, si-SPP-1, si-NC or OE-SPP-1, SW480 cells were seeded into 96-well plates at 3,000 cells/well density and cultured at $37^{\circ} \mathrm{C}$ for $1,2,3,4$ or 5 days. Cell proliferation was tested by using a Cell-Counting Kit 8 (CCK-8; Dojindo Molecular Technologies, Inc.) based on the manufacturer's description.

Apoptosis detection. The effect of SPP- $1 / \beta$-catenin axis on SW480 apoptosis was assessed by using the Annexin V/propidium iodide (PI) kit (Roche Diagnostics). After incubation with the Annexin V-FITC and PI solution in the dark for 15 min, SW480 cells were collected for flow cytometry using CytoFLEX (Beckman Coulter, Inc.) and cell apoptotic rates were analyzed by FlowJo 7.6 software (FlowJo LLC). FITC-/PI- quadrant were viable cells, $\mathrm{FITC}^{-} / \mathrm{PI}^{+}$were necrosis cells, FITC $^{+} / \mathrm{PI}^{-}$were early apoptotic cells and $\mathrm{FITC}^{+} / \mathrm{PI}^{+}$were late apoptotic cells.

In vivo tumor formation assay. SW480 cells were transfected with OE-NC+sh-NC, OE-SPP-1+sh-NC, OE-NC+sh-NC and $\mathrm{OE}-\mathrm{NC}+\mathrm{sh}-\beta$-catenin, and then incubated with $100 \mu \mathrm{g} / \mathrm{ml}$ $\mathrm{G} 418$ and $7 \mu \mathrm{g} / \mathrm{ml}$ puromycin for 14 days to establish the stable transfection cell lines. Then, $5 \times 10^{6}$ of the aforementioned cells were resuspended in PBS buffer and injected subcutaneously into the flanks of 4-6-week-old male nude mice $(n=20 ; 20 \pm 2 \mathrm{~g}$; Experimental Animal Center Of The Fourth Military Medical University). Mice were fed with common feed and sterile water ad libitum, and housed in $22 \pm 1^{\circ} \mathrm{C}$ with $55 \pm 1 \%$ humidity with a $12 \mathrm{~h}$ light/dark cycle. After 28 days of injection, mice were euthanized via cervical dislocation and the tumors were removed to weigh and photograph. Mice are considered as dead if the chests did not rise or fall and the hearts do not beat. Animal health and behavior were monitored every 4 days. Mice were sacrificed if the tumor diameter was $>1.8 \mathrm{~cm}$. No mouse died prior to the end of the study. These animal experiments were carried out in accordance to the Institutional principles for the concern and use of animals and the protocol was approved by The Ethical Committee of Ganzhou People's Hospital (approval no. Ky2019015).

Statistical analysis. Data are obtained from at least three times of independent experiments and expressed as means \pm standard deviation or median + interquartile range only for the IHC score. Comparison of the IHC scores between normal group and tumor group in Fig. 1A was carried out using the paired Wilcoxon signed rank test. Other comparisons between two groups were executed using two-tailed Student's t-tests and one-way ANOVA test followed by Tukey's post hoc test was used for multiple groups. A paired t-test was used for the analysis of tumor and adjacent non-tumor samples of the same individuals, and unpaired t-test was used for other comparisons between two groups. Kaplan-Meier analysis with log rank tests was used to evaluate the clinical significance of SPP-1 levels in predicting the prognosis of CRC patients. $\chi^{2}$ tests were used for the data comparisons listed in Table I. $\mathrm{P}<0.05$ was considered to indicate a statistically significant difference.

\section{Results}

Expression of SPP-1 is increased in CRC tissues and cells. To uncover the mechanism underlying SPP-1 in the progression of CRC, SPP-1 expression profiles were compared between CRC tissues and the adjacent normal colorectal tissues using IHC, RT-qPCR and western blotting assays. It was observed that the expression of SPP-1 was significantly increased at protein and mRNA levels in CRC tissues, compared with that in the normal tissues $(\mathrm{P}<0.01$ and $\mathrm{P}<0.001$, respectively; Fig. $1 \mathrm{~A}-\mathrm{C})$. Additionally, SPP-1 expression patterns in CRC cells and normal colon cells were evaluated using western blotting and RT-qPCR. The results demonstrated that SPP-1 expression in CRC cell lines SW620, COLO 205 and SW480 was significantly increased when compared with that in CCD-18Co cells at the mRNA $(\mathrm{P}<0.01$, Fig. 1D) and protein levels $(\mathrm{P}<0.01$, Fig. 1E). These findings confirmed that the expression of SPP-1 was increased in CRC.

Assessment of the clinical value of SPP-1 in CRC. To determine the clinical value of SPP-1 in CRC, Kaplan-Meier with log-rank analysis and $\chi^{2}$ tests test were used to analyze the effects of SPP-1 expression on the overall survival rate and the clinicopathological parameters of patients with CRC. As shown in Fig. 2, the overall survival rates for patients with SPP-1 low expression were significantly higher compared with that of patients with SPP-1 high expression. Moreover, SPP-1 expression level was associated with the differentiation of $\mathrm{CRC}$ tissues $(\mathrm{P}=0.017)$, and associated with TNM stage $(\mathrm{P}=0.001)$, incidence rates of tumor infiltration $(\mathrm{P}=0.001)$, lymph node metastasis $(\mathrm{P}=0.001)$, distant metastasis $(\mathrm{P}=0.001)$ and vascular invasion $(\mathrm{P}=0.001)$ (Table $\mathrm{I})$. These results indicated that SPP-1 played an important role 
Table I. Association between SPP-1 expression and the clinicopathological characteristics of 200 patients with colorectal cancer.

\begin{tabular}{|c|c|c|c|c|}
\hline Parameters & Total & Low expression & High expression & P-value \\
\hline Sex & & & & 0.689 \\
\hline Male & 102 & 45 & 57 & \\
\hline Female & 98 & 46 & 52 & \\
\hline Age, years & & & & 0.293 \\
\hline$<60$ & 48 & 25 & 23 & \\
\hline$\geq 60$ & 152 & 66 & 86 & \\
\hline Differentiation & & & & 0.017 \\
\hline High & 52 & 31 & 21 & \\
\hline Poor/moderation & 148 & 60 & 88 & \\
\hline TNM stage & & & & 0.001 \\
\hline $\mathrm{I} / \mathrm{II}$ & 46 & 40 & 6 & \\
\hline III/IV & 154 & 51 & 103 & \\
\hline Tumor infiltration & & & & 0.001 \\
\hline $\mathrm{T} 1 / \mathrm{T} 2$ & 32 & 26 & 6 & \\
\hline $\mathrm{T} 3 / \mathrm{T} 4$ & 168 & 65 & 103 & \\
\hline Lymph node metastasis & & & & 0.001 \\
\hline No & 53 & 38 & 15 & \\
\hline N1-N3 & 147 & 53 & 94 & \\
\hline Distant metastasis & & & & 0.001 \\
\hline M0 & 121 & 72 & 49 & \\
\hline M1 & 79 & 19 & 60 & \\
\hline Vascular invasion & & & & 0.001 \\
\hline Absent & 102 & 61 & 41 & \\
\hline Present & 98 & 30 & 68 & \\
\hline
\end{tabular}

TNM, Tumor-Node-Metastasis.

in predicting the clinical stage and prognosis in patients with CRC.

SPP-1 promotes proliferation and inhibits the apoptosis of CRC cells. SPP-1 expression was increased in SW620, COLO 205 and SW480 cells, and SW480 cell line was selected for further study as SPP-1-overexpression was most notable in these cells compared with SW620 and COLO 205. Compared with the control group, SPP-1 expression level was significantly decreased following transfection with si-SPP-1-1 and si-SPP-1-2, and OE-SPP-1 significantly enhanced SPP-1 expression at both the mRNA and protein levels $(\mathrm{P}<0.001$, Fig. 3A-D). Compared with the control group, downregulation of SPP-1 significantly inhibited cell proliferation, while overexpression of SPP-1 enhanced cell proliferation $(\mathrm{P}<0.05$, Fig. 3E). Besides, knockdown of SPP-1 significantly induced apoptosis, and overexpression of SPP-1 resulted in the opposite result $(\mathrm{P}<0.01$, Fig. 3F-G) as compared with the control group. These results verified that SPP-1 served as an oncogene in CRC.

SPP-1 promotes the expression of $\beta$-catenin and its nuclear transportation in CRC cells. To investigate whether Wnt/ $\beta$-catenin signaling was involved in SPP-1-mediated
CRC progression, the effects of SPP-1 on the activation of Wnt/ $\beta$-catenin signaling were assessed. Western blotting showed that SPP-1-overexpression significantly increased the expression of $\beta$-catenin and c-myc, whereas no obvious influence on the expression levels of Frz, DVL1, APC, Axin and TCF in SW480 cells were observed (P<0.001, Fig. 4A). The Co-IP assay showed that SPP-1 could combine with $\beta$-catenin protein (Fig. 4B). Additionally, SPP-1-overexpression promoted the nuclear accumulation of $\beta$-catenin (Fig. 4C). These results suggested that SPP-1 triggered the activation of $\beta$-catenin signaling.

SPP-1 facilitates CRC progression in a $\beta$-catenin-dependent manner. Finally, it was assessed whether $\beta$-catenin was involved in SPP-1-mediated CRC progression. Three shRNAs of $\beta$-catenin were applied to downregulate $\beta$-catenin expression in CRC cells, among which shRNA-1 significantly deceased $\beta$-catenin mRNA and protein expression levels compared with the sh-NC group $(\mathrm{P}<0.001$, Fig. 5A and $\mathrm{B})$. Downregulation of $\beta$-catenin in SPP-1 overexpressed cells significantly rescued the enhancement in cell proliferation induced by SPP-1 in SW480 cells $(\mathrm{P}<0.01$, Fig. 5C), and increased apoptosis rate $(\mathrm{P}<0.01$, Fig. 5D) compared with the OE-SPP-1+sh-NC group. Furthermore, SPP-1 stable overexpression in SW480 cells 

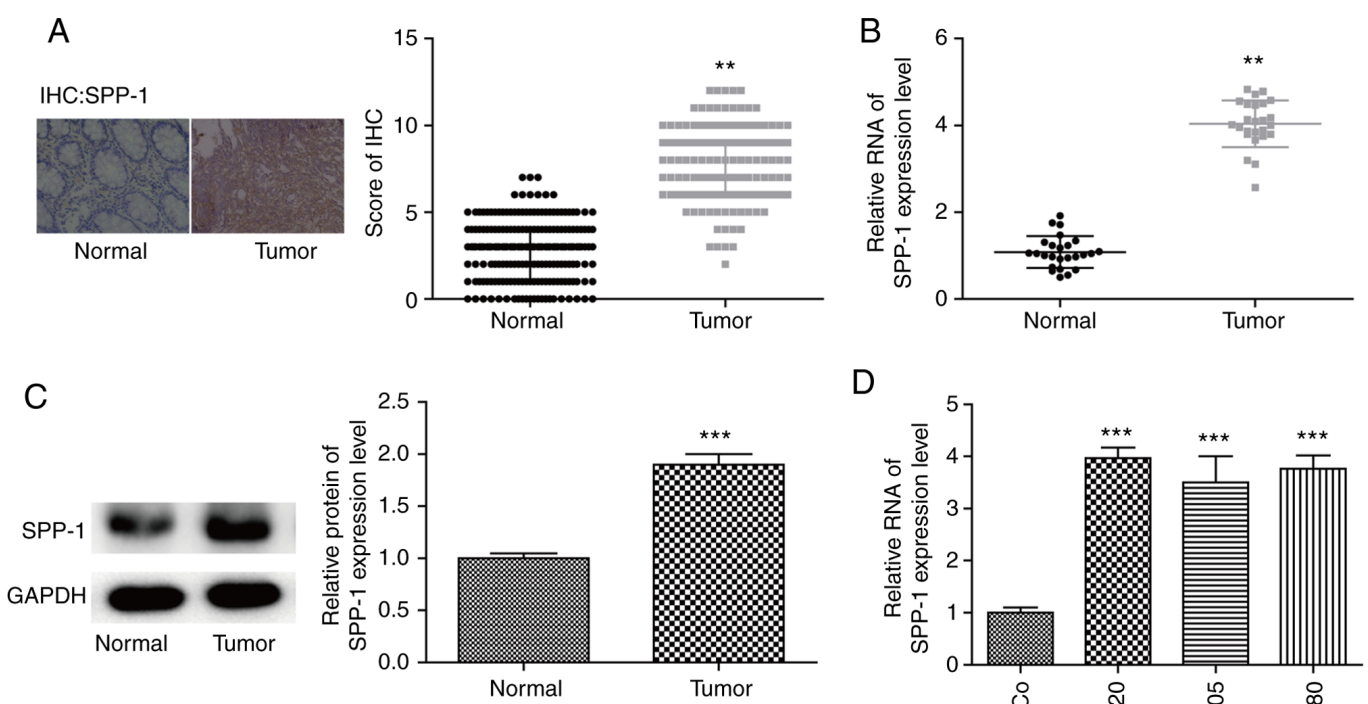

D
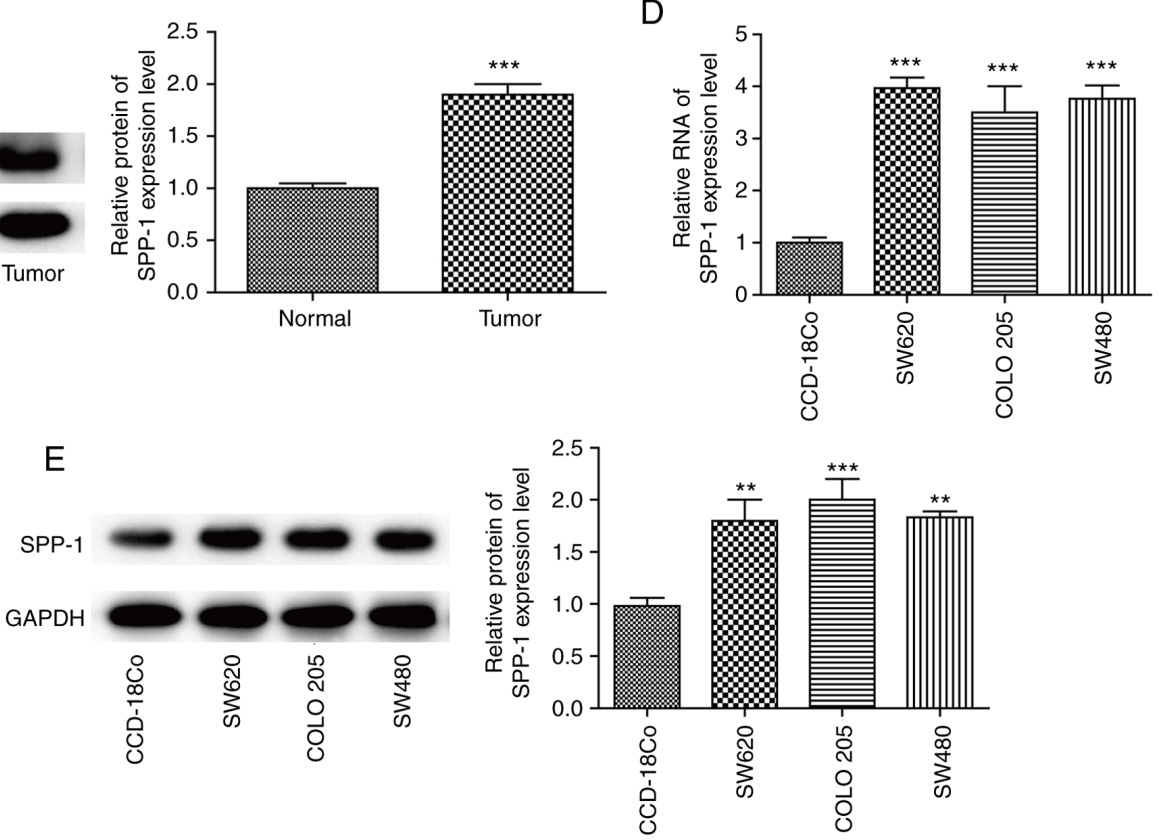

Figure 1. Increased expression of SPP-1 in CRC tissues and cells. (A) Representative images of protein expression of SPP-1 detected using immunohistochemical analysis of CRC and paired normal tissues (magnification, x20). SPP-1 mRNA and protein levels in 25 paired CRC tissues and the normal tissues were determined using (B) RT-qPCR and (C) and western blotting ( $\mathrm{n}=25)$. SPP-1 expression patterns in normal colorectal cells and CRC cells were examined using (D) RT-PCR and (E) western blotting assays $(n=3){ }^{* *} \mathrm{P}<0.01,{ }^{* * * *} \mathrm{P}<0.001$ vs. control. RT-q, reverse transcription-quantitative; SPP-1, secreted phosphoprotein-1 .

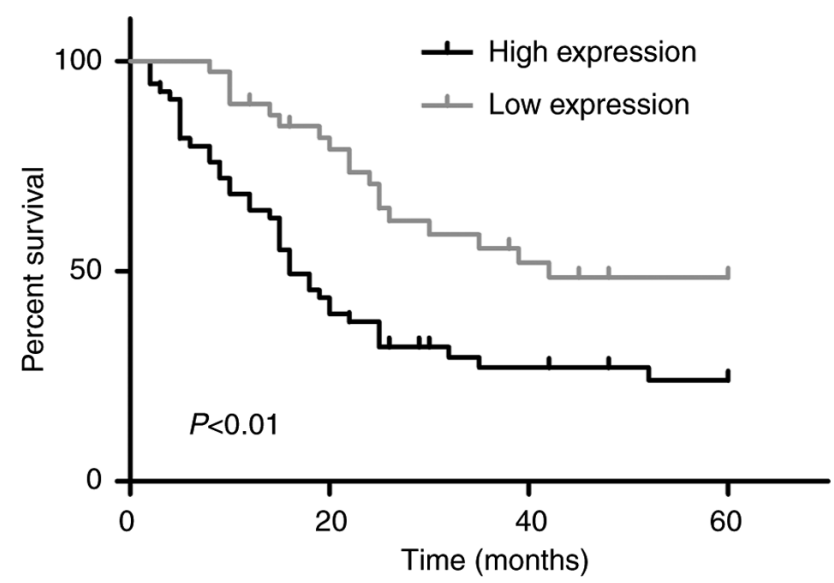

Figure 2. Evaluation of SPP-1 expression in predicting the prognosis of patients with CRC. Kaplan-Meier curve with log-rank analysis was conducted to assess the overall survival rates for patients with $\mathrm{CRC}$ with high and low SPP-1 expression. SPP-1, secreted phosphoprotein-1; CRC, colorectal cancer.

significantly promoted tumor formation in vivo as compared with the OE-NC+sh-NC group, which was abolished when $\beta$-catenin was stably downregulated $(\mathrm{P}<0.01$, Fig. $5 \mathrm{E}$ and $\mathrm{F})$. Additionally, the largest tumor size was $\sim 0.18 \mathrm{~cm}^{3}$ and the largest tumor diameter was $\sim 1.0 \mathrm{~cm}$ (Fig. $5 \mathrm{~F}$ ). These results suggested that SPP-1 facilitated CRC progression in a $\beta$-catenin-dependent manner.

\section{Discussion}

SPP-1 has been previously demonstrated to be highly expressed in CRC cells and tissues (22), and overexpression of SPP-1 significantly enhances cell proliferation and motility in vitro, and tumorigenesis and angiogenesis in vivo (23). In addition, high SPP-1 expression predicts a poor prognosis in patients with CRC (24). These findings suggest that SPP-1 serves an important role in human CRC. The present study demonstrated, for the first time, that SPP-1 facilitated the progression of CRC through interacting with $\beta$-catenin and increasing its expression and nuclear accumulation.

SPP-1 is a secreted glycophosphoprotein, which is expressed in multiple cell types, and is strongly implicated in numerous biological functions, such as cell adhesion, migration, bone calcification, immune responses and carcinogenesis $(25,26)$. Up to now, several studies have recognized that SPP-1 is overexpressed in multiple types of cancer and its high expression is associated with poor prognosis and advanced clinical process. For example, the plasma SPP-1 level is significantly elevated in patients with renal cell carcinoma with distant metastasis, and SPP-1 high 

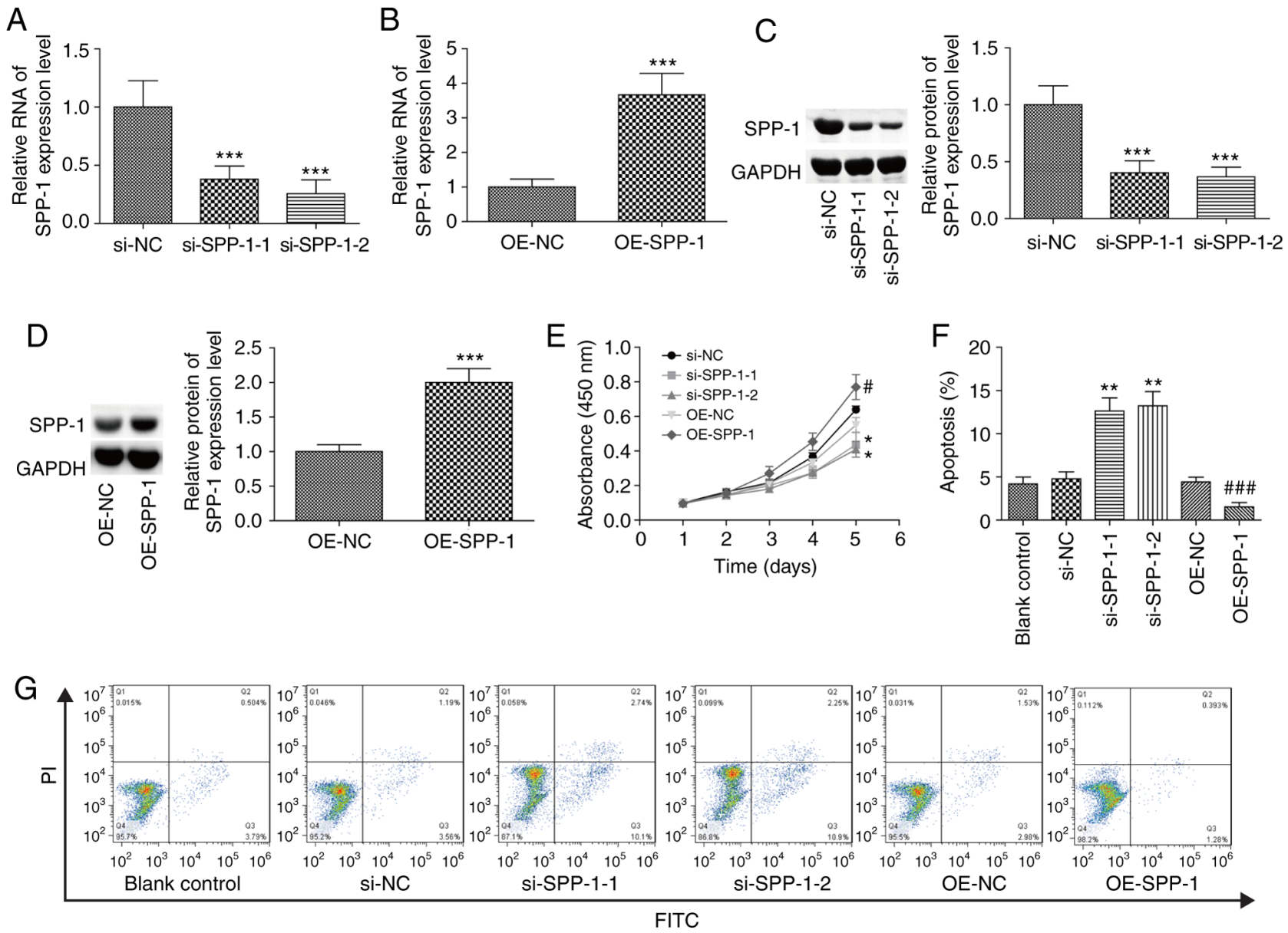

Figure 3. Increased expression of SPP-1 enhances cell proliferation and reduces apoptosis. SW480 cells were transiently transfected with OE-SPP-1, OE-NC, si-SPP-1 and si-NC, then (A-B) mRNA levels were determined using RT-PCR and (C-D) protein levels were measured by western blotting at $48 \mathrm{~h}$ post-treatments. (E) A Cell Counting Kit-8 assay was performed to assess the effects of altered expression of SPP-1 on the cell proliferation. (F and G) Flow cytometry was carried out to detect apoptosis $(\mathrm{n}=3)$. ${ }^{\mathrm{P}} \mathrm{P}<0.05,{ }^{* *} \mathrm{P}<0.01$ and ${ }^{* * *} \mathrm{P}<0.001$ vs. si-NC group; ${ }^{*} \mathrm{P}<0.05,{ }^{\# \# \#} \mathrm{P}<0.001$ vs. OE-NC group. SPP-1, secreted phosphoprotein 1; OE, overexpression, $\mathrm{NC}$, negative control; si, small interfering.

expression levels predicts a lower survival rate (27). SPP-1 is upregulated in oral squamous cell carcinoma (OSCC) and stromal OSCC cells, which predicts a higher nodal stage, higher World Health Organization clinical stage and poor clinical prognosis in patients with OSCC (28). In addition, Loosen et al (29) reported that the increased expression of SPP-1 is associated with the poor survival in patients with postoperative cholangiocarcinoma. Similarly, in CRC, the high expression profile of SPP-1 is significantly correlated with the lymph node metastasis, lymphatic/venous invasion and TNM stage, as well as poor prognosis $(22,30)$. Consistently, the current study demonstrated that the high expression level of SPP-1 was closely associated with a lower overall survival rate and advanced clinical process of patients with CRC, including TNM stage, tumor infiltration, lymph node metastasis, distant metastasis and vascular invasion. This suggested that SPP-1 may have value as a biomarker for CRC diagnosis and prognosis prediction.

SPP-1 has been identified to serve as an inducer of the aggressive behaviors in several types of tumor cell, including CRC. For example, Xu et al (17) reported that knockdown of SPP-1 significantly represses the proliferation, colony formation, migration and in vivo tumor growth and increased apoptosis in CRC cells. Likui et al (31) demonstrated that
SPP-1-downregulation significantly suppresses invasion and enhances the radiosensitivity of CRC cells. Huang et al (32) demonstrated that SPP-1-overexpression significantly promotes the hepatic metastasis of CRC. These findings indicate that SPP-1 plays an important role in promoting CRC progression. Except for the oncogenic role of SPP-1 in $\mathrm{CRC}$, the present study also clarified that SPP-1 promoted the expression and nuclear accumulation of the $\beta$-catenin protein through protein-protein interactions. SPP-1 has been reported to induce the phosphorylation of GSK-3 $\beta$ at serine 9, which is the most well recognized means for GSK-3 $\beta$ inhibition (33), suggesting that SPP-1 may induce $\beta$-catenin expression through repressing GSK-3 $\beta$. Moreover, Robertson et al (34) demonstrated that SPP-1-upregulation could significantly promote the expression and nuclear accumulation of $\beta$-catenin, potentially through repressing GSK-3 $\beta$ expression. The present study observed that SPP-1 could combine with $\beta$-catenin protein and promote its expression with no obvious influence in the expression of DVL1, Frz, TCF, Axin and APC. Evidence has shown that the increased expression of TCF4/lymphoid enhancer-binding factor induced by $\beta$-catenin activation can promote SPP-1 transcription $(24,35)$. Taken together, it was speculated that there might be a positive feedback between SPP-1 and 

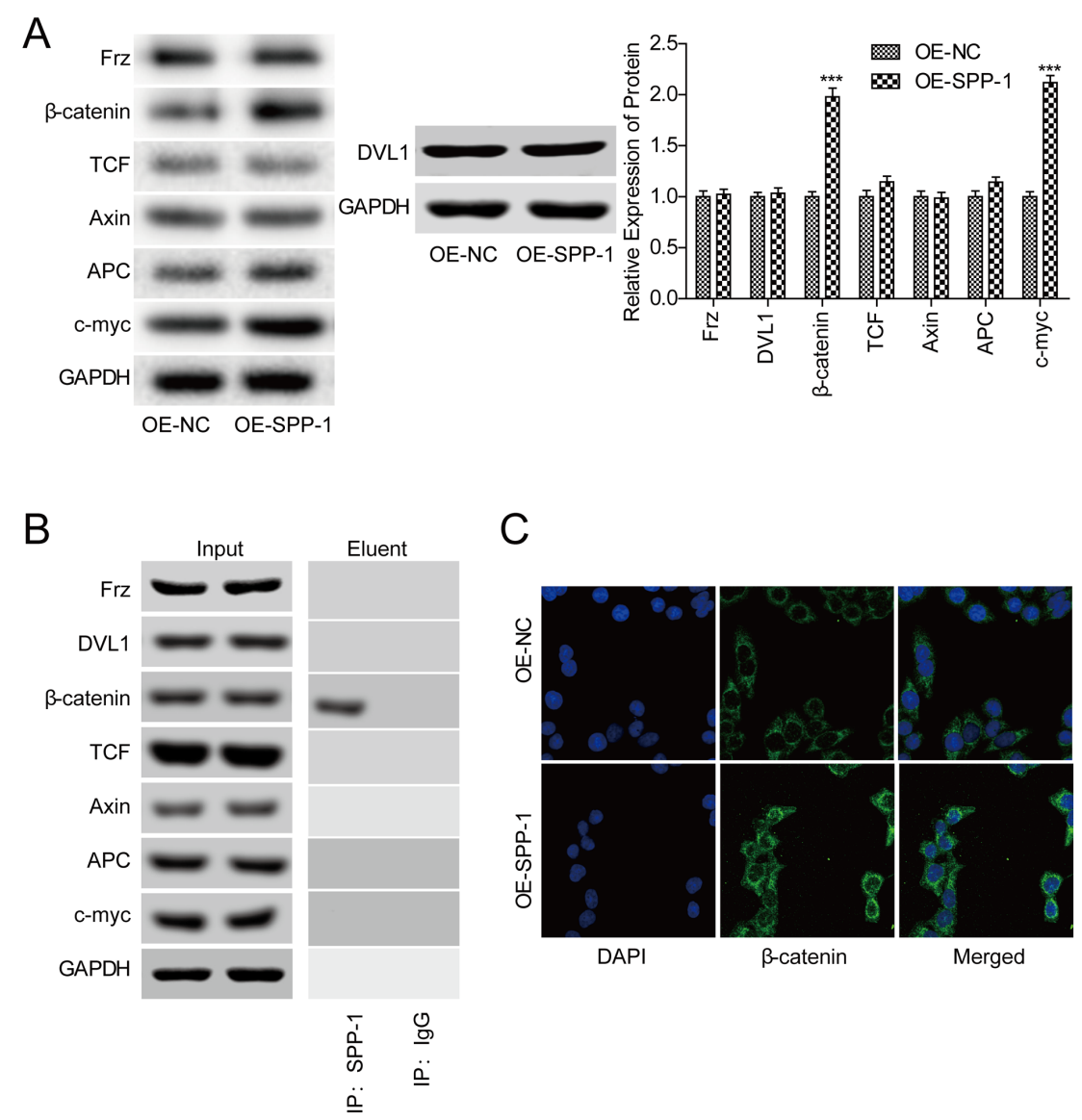

Figure 4. Increased expression of SPP-1 increases $\beta$-catenin expression and nuclear transportation. (A) Expression of Frz, DVL1, $\beta$-catenin, TCF, Axin, APC and c-myc were detected using western blotting after SW480 cells were infected OE-SPP-1 and OE-NC (n=3). (B) A co-immunoprecipitation assay was performed to assess the interactions between SPP-1 and Frz, DVL1, $\beta$-catenin, TCF, Axin, APC and c-myc. C) Immunofluorescence microscopy was used to detect the effects of SPP-1 on the subcellular location of $\beta$-catenin. ${ }^{* * * *} \mathrm{P}<0.001$ vs. OE-NC. SPP-1, secreted phosphoprotein-1; OE, overexpression; NC, negative control; APC, adenomatous polyposis coil; Axis, axin inhibitor.
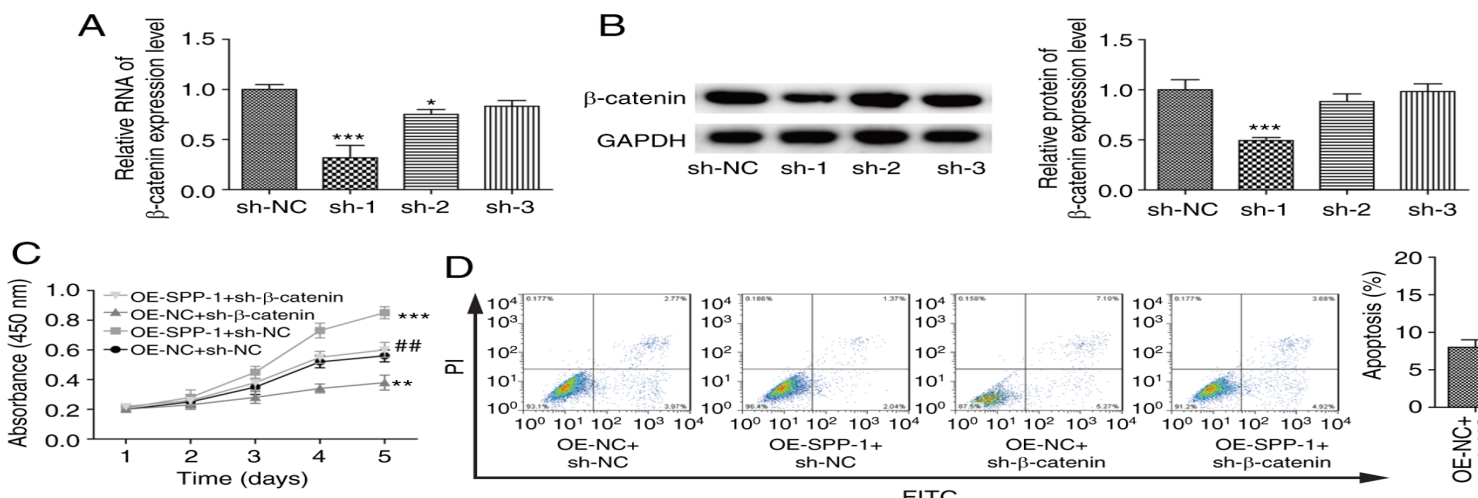

D
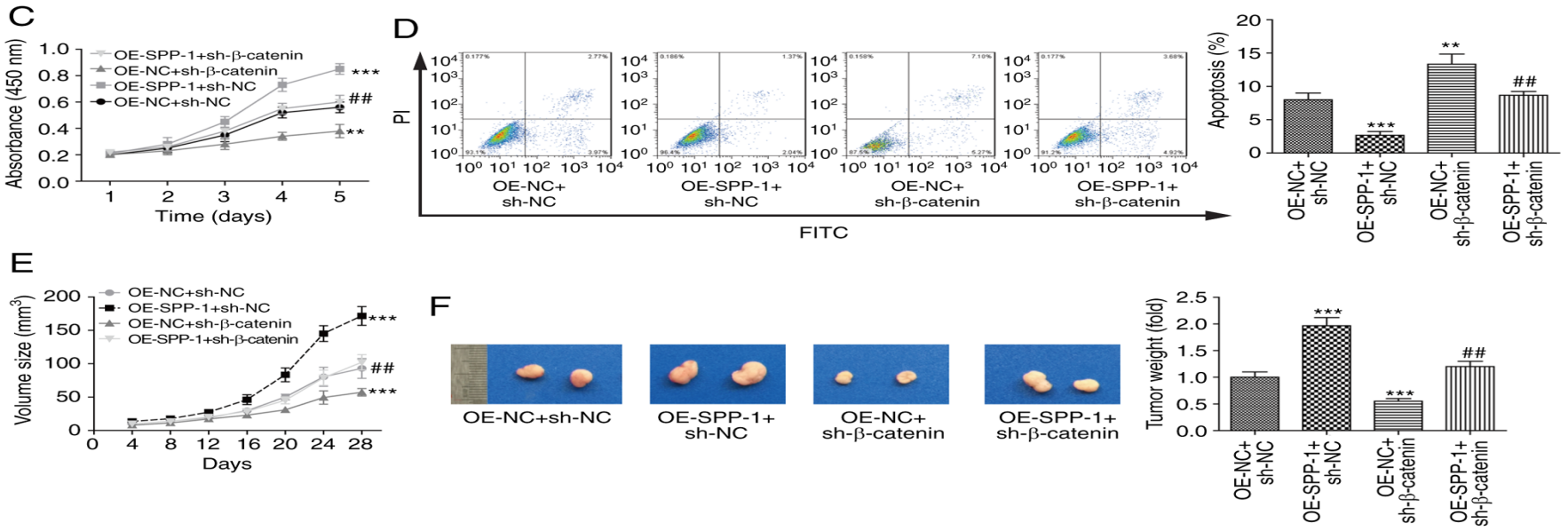

Figure 5. Effects of SPP-1/ $\beta$-catenin signaling on cell proliferation, apoptosis and tumorigenesis. Knockdown efficiency of sh- $\beta$-catenin in SW480 cells was determined using (A) reverse transcription-quantitative PCR and (B) western blotting ( $n=3,{ }^{*} \mathrm{P}<0.05,{ }^{* * *} \mathrm{P}<0.001$, vs. sh-NC group). SW480 cells were treated with OE-NC+sh-NC, OE-NC+sh- $\beta$-catenin, OE-SPP-1+sh-NC and OE-SPP-1+sh- $\beta$-catenin, then cell proliferation was determined using a (C) Cell Counting Kit-8 assay and (D) apoptosis was assessed using flow cytometry ( $\mathrm{n}=3$ ). (E and F) In vivo tumor formation ability was determined by nude mice xenotransplantation assays $(\mathrm{n}=5) .(\mathrm{C}-\mathrm{F}){ }^{* *} \mathrm{P}<0.01,{ }^{* * *} \mathrm{P}<0.001$ vs. OE-NC+sh-NC group; ${ }^{\# \#} \mathrm{P}<0.01$ vs. OE-SPP-1+sh-NC group. SPP-1 secreted phosphoprotein 1 ; $\mathrm{OE}$, overexpression; $\mathrm{NC}$, negative control; sh, short hairpin. 
$\beta$-catenin, which needs to be verified in future studies using western blotting assays.

To further explore the role of $\beta$-catenin in SPP-1 induced CRC progression, flow cytometry, CCK-8 and in vivo tumor formation assays were performed. The results showed that the enhancements in cell proliferation, tumorigenesis and apoptosis inhibition induced by SPP-1-overexpression were abrogated when $\beta$-catenin was downregulated. These results demonstrated that $\beta$-catenin activation plays an important role in SPP-1-mediated CRC progression.

Drug resistance is a main cause for the dissatisfaction of CRC treatment (36), thus it is important to reveal the mechanisms of drug resistance in CRC. One main limitation of the present study is that the role of SPP-1 was not explored in response to anticancer drugs, such as cis-platin-mediated apoptosis of CRC cells. Further in vitro and in vivo experiments should be carried out to disclose SPP-1 role in the drug resistance of CRC.

In conclusion, the current study demonstrated that SPP-1 functions as an oncogene in $\mathrm{CRC}$, which is highly expressed in CRC tissues and cells and is closely associated with the malignant clinical progression and poor outcome of patients with CRC. In addition, SPP-1 confers CRC cells with malignant phenotype in a $\beta$-catenin dependent manner. Overall, the present study provides evidence to support the value of SPP-1/ $\beta$-catenin as a novel therapeutic target for human CRC.

\section{Acknowledgements}

Not applicable.

\section{Funding}

No funding was received.

\section{Availability of data and materials}

All data generated or analyzed during this study are included in this published article.

\section{Authors' contributions}

CF conceived the project and revised the manuscript. JY and YL performed the experiments, collected and interpreted the data and wrote the manuscript. LZ analyzed the data. CF, JY, YK and LZ confirm the authenticity of all raw data. All authors read and approved the final manuscript.

\section{Ethics approval and consent to participate}

This study was approved by The Ethical Committee of Ganzhou People's Hospital (approval no. Ky2019015). All patients provided written informed consent.

\section{Patient consent for publication}

Not applicable.

\section{Competing interests}

The authors declare that they have no competing interests.

\section{References}

1. Siegel RL, Miller KD, Fedewa SA, Ahnen DJ, Meester RGS, Barzi A and Jemal A: Colorectal cancer statistics, 2017. CA Cancer J Clin 67: 177-193, 2017.

2. Bever KM and Le DT: An expanding role for immunotherapy in colorectal cancer. J Natl Compr Canc Netw 15: 401-410, 2017.

3. Bode AM, Dong Z and Wang H: Cancer prevention and control: Alarming challenges in China. Natl Sci Rev 3: 117-127, 2016.

4. Jacome AA and Eng C: Role of immune checkpoint inhibitors in the treatment of colorectal cancer: Focus on nivolumab. Expert Opin Biol Ther 19: 1247-1263, 2019.

5. Qi J, Yu Y, Akilli Ozturk O, Holland JD, Besser D, Fritzmann J, Wulf-Goldenberg A, Eckert K, Fichtner I and Birchmeier W: New Wnt $/ \beta$-catenin target genes promote experimental metastasis and migration of colorectal cancer cells through different signals. Gut 65: 1690-1701, 2016.

6. Lee K, Lindsey AS, Li N, Gary B, Andrews J, Keeton AB and Piazza GA: $\beta$-catenin nuclear translocation in colorectal cancer cells is suppressed by PDE10A inhibition, cGMP elevation, and activation of PKG. Oncotarget 7: 5353-5365, 2016.

7. Larriba MJ, Valle N, Palmer HG, Ordóñez-Morán P, Alvarez-Díaz S, Becker KF, Gamallo C, de Herreros AG, González-Sancho JM and Muñoz A: The inhibition of Wnt/beta-catenin signalling by 1alpha,25-dihydroxyvitamin D3 is abrogated by Snaill in human colon cancer cells. Endocr Relat Cancer 14: 141-151, 2007.

8. Sebio A, Kahn M and Lenz HJ: The potential of targeting Wnt/ $\beta$-catenin in colon cancer. Expert Opin Ther Targets 18: 611-615, 2014.

9. Arce L, Yokoyama NN and Waterman ML: Diversity of LEF/TCF action in development and disease. Oncogene 25: 7492-7504, 2006.

10. Zhang S, Li Y, Wu Y, Shi K, Bing L and Hao J: Wnt/ $/$-catenin signaling pathway upregulates c-Myc expression to promote cell proliferation of P19 teratocarcinoma cells. Anat Rec (Hoboken) 295: 2104-2113, 2012.

11. Dow LE, O'Rourke KP, Simon J, Tschaharganeh DF, van Es JH, Clevers $\mathrm{H}$ and Lowe SW: Apc restoration promotes cellular differentiation and reestablishes crypt homeostasis in colorectal cancer. Cell 161: 1539-1552, 2015.

12. Brabletz T, Jung A, Reu S, Porzner M, Hlubek F, Kunz-Schughart LA, Knuechel R and Kirchner T: Variable beta-catenin expression in colorectal cancers indicates tumor progression driven by the tumor environment. Proc Natl Acad Sci USA 98: 10356-10361, 2001.

13. Phelps RA, Chidester S, Dehghanizadeh S, Phelps J, Sandoval IT, Rai K, Broadbent T, Sarkar S, Burt RW and Jones DA: A two-step model for colon adenoma initiation and progression caused by APC loss. Cell 137: 623-634, 2009.

14. Kang YS, Jeong EJ, Seok HJ, Kim SK, Hwang JS, Choi ML, Jo DG, Kim Y, Choi J, Lee YJ, et al: Cks1 regulates human hepatocellular carcinoma cell progression through osteopontin expression. Biochem Biophys Res Commun 508: 275-281, 2019.

15. Ouyang X, Huang Y, Jin X, Zhao W, Hu T, Wu F and Huang J: Osteopontin promotes cancer cell drug resistance, invasion, and lactate production and is associated with poor outcome of patients with advanced non-small-cell lung cancer. Onco Targets Ther 11: 5933-5941, 2018.

16. Ferreira LB, Eloy C, Pestana A, Lyra J, Moura M, Prazeres H, Tavares C, Sobrinho-Simões M, Gimba E and Soares P: Osteopontin expression is correlated with differentiation and good prognosis in medullary thyroid carcinoma. Eur J Endocrinol 174: 551-561, 2016.

17. Xu C, Sun L, Jiang C, Zhou H, Gu L, Liu Y and Xu Q: SPP1, analyzed by bioinformatics methods, promotes the metastasis in colorectal cancer by activating EMT pathway. Biomed Pharmacother 91: 1167-1177, 2017.

18. Huang RH, Quan YJ, Chen JH, Wang TF, Xu M, Ye M, Yuan H Zhang CJ, Liu XJ and Min ZJ: Osteopontin promotes cell migration and invasion, and inhibits apoptosis and autophagy in colorectal cancer by activating the p38 MAPK signaling pathway. Cell Physiol Biochem 41: 1851-1864, 2017.

19. Edge SB and Compton CC: The American joint committee on cancer: The 7th edition of the AJCC cancer staging manual and the future of TNM. Ann Surg Oncol 17: 1471-1474, 2010.

20. Xin B, He X, Wang J, Cai J, Wei W, Zhang T and Shen X: Nerve growth factor regulates CD133 function to promote tumor cell migration and invasion via activating ERK1/2 signaling in pancreatic cancer. Pancreatology 16: 1005-1014, 2016. 
21. Livak KJ and Schmittgen TD: Analysis of relative gene expression data using real-time quantitative PCR and the 2(-Delta Delta C(T)) method. Methods 25: 402-408, 2001.

22. Likui W, Hong W and Shuwen Z: Clinical significance of the upregulated osteopontin mRNA expression in human colorecta cancer. J Gastrointest Surg 14: 74-81, 2010.

23. Irby RB, McCarthy SM and Yeatman TJ: Osteopontin regulates multiple functions contributing to human colon cancer development and progression. Clin Exp Metastasis 21: 515-523, 2004.

24. Rohde F, Rimkus C, Friederichs J, Rosenberg R, Marthen C, Doll D, Holzmann B, Siewert JR and Janssen KP: Expression of osteopontin, a target gene of de-regulated Wnt signaling, predicts survival in colon cancer. Int J Cancer 121: 1717-1723, 2007.

25. Denhardt DT and Guo X: Osteopontin: A protein with diverse functions. FASEB J 7: 1475-1482, 1993.

26. Denhardt DT, Giachelli CM and Rittling SR: Role of osteopontin in cellular signaling and toxicant injury. Annu Rev Pharmacol Toxicol 41: 723-749, 2001.

27. Ramankulov A, Lein M, Kristiansen G, Meyer HA, Loening SA and Jung K: Elevated plasma osteopontin as marker for distant metastases and poor survival in patients with renal cell carcinoma. J Cancer Res Clin Oncol 133: 643-652, 2007.

28. Avirovic M, Matusan-Ilijas K, Damante G, Fabrro D, Cerović R Juretić M, Grahovac B, Jonjić N and Lučin K: Osteopontin expression is an independent factor for poor survival in oral squamous cell carcinoma: A computer-assisted analysis on TMA sections. J Oral Pathol Med 42: 620-626, 2013.
29. Loosen SH, Roderburg C, Kauertz KL, Pombeiro I, Leyh C, Benz F, Vucur M, Longerich T, Koch A, Braunschweig T, et al: Elevated levels of circulating osteopontin are associated with a poor survival after resection of cholangiocarcinoma. J Hepatol 67: 749-757, 2017.

30. Wei R, Wong JPC, Lyu P, Xi X, Tong O, Zhang SD, Yuen HF, Shirasawa $S$ and Kwok HF: In vitro and clinical data analysis of Osteopontin as a prognostic indicator in colorectal cancer. J Cell Mol Med 22: 4097-4105, 2018.

31. Likui W, Hong W, Shuwen Z, Yuangang Y and Yan W: The potential of osteopontin as a therapeutic target for human colorectal cancer. J Gastrointest Surg 15: 652-659, 2011.

32. Huang J, Pan C,Hu H,Zheng S and Ding L: Osteopontin-enhanced hepatic metastasis of colorectal cancer cells. PLoS One 7: e47901, 2012.

33. McManus EJ, Sakamoto K, Armit LJ, Ronaldson L, Shpiro N, Marquez R and Alessi DR: Role that phosphorylation of GSK3 plays in insulin and Wnt signalling defined by knockin analysis. EMBO J 24: 1571-1583, 2005.

34. Robertson BW and Chellaiah MA: Osteopontin induces beta-catenin signaling through activation of Akt in prostate cancer cells. Exp Cell Res 316: 1-11, 2010.

35. El-Tanani MK, Barraclough R, Wilkinson MC and Rudland PS: Regulatory region of metastasis-inducing DNA is the binding site for T cell factor-4. Oncogene 20: 1793-1797, 2001

36. Van der Jeught K, Xu HC, Li YJ, Lu XB and Ji G: Drug resistance and new therapies in colorectal cancer. World J Gastroenterol 24: 3834-3848, 2018 